$$
\text { CONF-9605110--2 }
$$

\title{
LA-UR- $96-1423$
}

Title:

RADIO FREQUENCY ASSISTED CHEMICAL VAPOR INFILTRATION

Author(s):

Submitted to:

David J. Devlin, MST-7

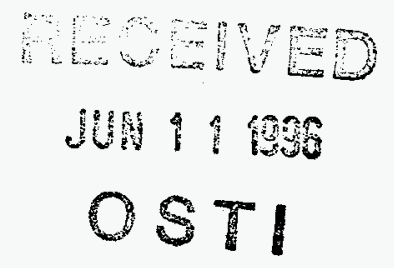

\section{Robert S. Barbero, MST-7 DISCLAIMER}

Kerry N. Siebein, MST-7

This report was prepared as an account of work sponsored by an agency of the United States Government. Neither the United States Government nor any agency thereof, nor any of their employees, makes any warranty, express or implied, or assumes any legal liability or responsibility for the accuracy, completeness, or usefulness of any information, apparatus, product, or process disclosed, or represents that its use would not infringe privately owned rights. Reference herein to any specific commercial product, process, or service by trade name, trademark, manufacturer, or otherwise does not necessarily constitute or imply its endorsement, recommendation, or favoring by the United States Government or any agency thereof. The views and opinions of authors expressed herein do not necessarily state or reflect those of the United States Government or any agency thereof.

\section{3th International Conference of}

Chemical Vapor Deposition

Los Angeles, CA

May 1996

\section{MASTER}

\section{Los Alamos}

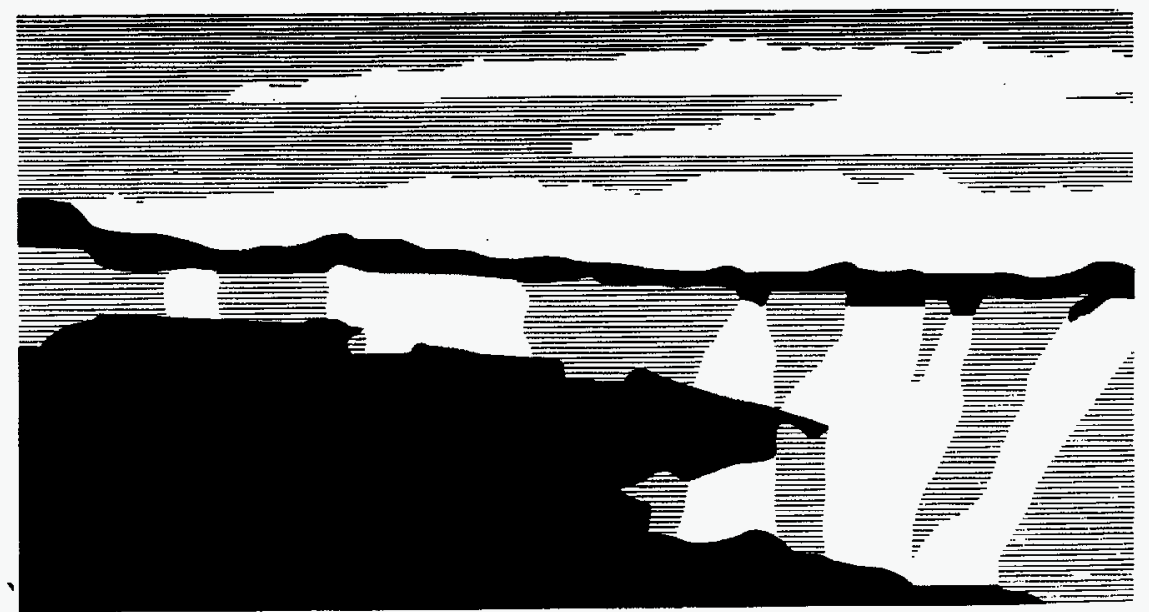

NATIONAL LABORATOR

Los Alamos National Laboratory, an affirmative action/equal opportunity employer, is operated by the University of California for the U.S. Department of Energy under contract W-7405-ENG-36. By acceptance of this article, the publisher recognizes that the U.S. Government retains a nonexclusive, royalty-free license to publish or reproduce the published form of this contribution, or to allow others to do so, for U.S. Government purposes. The Los Alamos National Laboratory requests that the publisher identify this article as work performed under the auspices of the U.S. Department of Energy. 


\section{DISCLADMER}

Portions of this document may be illegible in electronic image products. Images are produced from the best available original document. 


\title{
Radio Frequency Assisted Chemical Vapor Infiltration
}

\author{
David J. Devlin, Robert S. Barbero, Kerry N. Siebein \\ Materials Science and Technology Division \\ Los Alamos National Laboratory \\ Los Alamos, NM 87545
}

\begin{abstract}
A process for the rapid densification of carbon/carbon composites has been developed. The method makes use of the direct radio frequency heating of three dimensional carbon preforms to establish inverted thermal gradients. Rapid densification from the inside-out, of $2.5 \mathrm{~cm}$. diameter parts, in as little as 30 hours was demonstrated. A simple model is used to predict the initial thermal gradients and is compared to experimental measurements. The results are discussed in terms of frequency, part dimension and radiative heat loss.
\end{abstract}

\section{INTRODUCTION}

Advanced fiber reinforced refractory composites such as carbon/carbon and ceramic matrix composites offer many advantages over conventional materials. These include high strength, at elevated temperatures, low density, corrosion resistance and good wear properties. Carbon/carbon composites have been successfully used in a number of important applications for the past 25 years. Despite the maturity of these markets few advances in processing methods have been made. One of the established methods of carbon/carbon composite manufacturing is chemical vapor infiltration. As is well known, the conventional isothermal process with it's reduced pressures, reactant dilution and low temperatures is time consuming. These conditions are required to insure a uniform infiltration through out the part. Large kilns with hundreds of parts are typically processed in a batch fashion taking advantage of economy of scale. Long processing times extending to several months are typical. Recent efforts aimed at the development of faster processes have had some success. Methods such as forced flow, thermal gradient, pulsed flow and various combination of these techniques have been explored(1). Most of these have been applied to ceramic matrix composites. Recently we have reported a microwave assisted CVI technique which takes advantage of the volumetric heating effects that are possible with microwave heating of ceramic materials(2). Inverted thermal gradients are formed in the preform allowing for rapid CVI processing of 3-D parts. The application of this technique to carbon materials with radio frequency heating is subject of this paper.

Advantages in using electromagnetic energy in CVI are the ability to couple energy directly into the substrate with the possibility of heating the substrate volumetrically. Volumetric heating, together with heat losses at the surfaces due to radiation and convection, gives rise to "inverted" thermal gradients. With the internal region of the 
substrate hot, cool reactant gases penetrate inward prior to the onset of the deposition reaction. Consequently, deposition can occur from the inside-out. Inside-out densification minimizes premature pore closure in outer regions, resulting in a spatially uniform composite. Decreases in processing time are also possible. A cold wall reactor will minimize unwanted deposition on the walls and fixtures and reduce gas phase nucleation thereby saving on reactant costs, minimizing waste production and allowing for higher pressure processing.

\section{Thermal Gradients by Electromagnetic Heating.}

The concept for the production of inverted gradients is illustrated in figure 1. Ordinary radiant heating results in rapid attenuation of the radiation at the surface. Moving down in frequency to the microwave and RF regions of the spectrum the penetration of the radiation into the part increases. The magnetic intensity of the electromagnetic wave decays exponentially with increasing distance into the part. For induction heating the current induced falls off in a similar manner and is characterized as a skin or current depth given by the following relation:

$$
\delta=(1 / \pi f \mu \sigma)^{1 / 2}
$$

where:

$\mathrm{f}$ is the frequency $\mathrm{Hz}$,

$\mu$ magnetic permeability $\mathrm{H} / \mathrm{m}$

$\sigma$ is the electrical conductivity $\Omega^{-1} \mathrm{~m}^{-1}$

Thus the degree of volumetric heating depends on the frequency and electrical conductivity of the material. For a carbon fiber preform the electrical conductivity is estimated at 25,000 $\Omega^{-1} \mathrm{~m}^{-1}(3)$. Using this value the variation in current depth with frequency is shown in figure 2. Processing of carbon materials with large dimensions will require frequencies in the $10 \mathrm{kHz}$ range. As illustrated the power distribution penetrates the interior resulting in volumetric heating. The temperature distribution falls off at the surface due to radiative and convective losses leading to an inverted temperature gradient. For the deposition of carbon from methane, a difference in temperature of $200^{\circ} \mathrm{C}$ can reduce the deposition rate by a factor of 150 near the exterior surface surface of thr preform resulting in deposition from the inside-out.

Based on the classical heat flow equation (4) for a cylinder of radius $\mathbf{a}$, the temperature distribution can be expressed by the following equation :

$$
\begin{aligned}
& \theta_{r}-\theta_{c}=\frac{P_{a}}{2 k_{c}}\left[\frac{r^{2}}{a^{2}}-\frac{1}{k_{2}}\left(\frac{X\left(k_{2} r / a\right)-1}{Z\left(k_{2}\right)}\right)\right] \\
& X\left(k_{2} r / a\right)=\operatorname{ber}^{2}\left(\mathrm{k}_{2} \mathrm{r} / \mathrm{a}\right)+\operatorname{bei}^{2}\left(\mathrm{k}_{2} \mathrm{r} / \mathrm{a}\right) \\
& Z\left(k_{2}\right)=\operatorname{ber}\left(\mathrm{k}_{2}\right) \operatorname{ber}^{\prime}\left(\mathrm{k}_{2}\right)+\operatorname{bei}\left(\mathrm{k}_{2}\right) \text { bei' }^{\prime}\left(\mathrm{k}_{2}\right)
\end{aligned}
$$

ber and bei are the kelvin functions. 
and: $\quad \mathrm{k}_{2}=\mathrm{k}_{1} \mathrm{a}$

$\mathrm{k}_{1}=\sqrt{ } 2 / \delta$

$\mathrm{P}_{\mathrm{a}}=$ the total power absorbed $\mathrm{w} / \mathrm{m}^{2}$

$\theta_{\mathrm{r}}$ and $\theta_{\mathrm{c}}=$ the radial and centerline temperatures

$\mathrm{k}_{\mathrm{c}}=$ thermal conductivity $\mathrm{w} / \mathrm{m}{ }^{\circ} \mathrm{K}$

Equation 2 can be modified to account for heat loss at the surface by defining a radiation correction factor $\mathrm{P}_{\mathrm{n}} / \mathrm{P}_{\mathrm{a}}$.

where: $P_{n}$ is net power absorbed after radiation $w / \mathrm{m}^{2}$

The temperature distribution through the cylindrical preform is given by:

$$
\theta_{r}-\theta_{c}=\frac{P_{n}}{2 k_{c}}\left[\frac{r^{2}}{a^{2}}-\left[\frac{1}{P_{n} / P_{a}}\right] \frac{1}{k_{2}}\left(\frac{X\left(k_{2} r / a\right)-1}{Z\left(k_{2}\right)}\right)\right]
$$

Figure 3 shows a dimensionless plot of equation 3 for various values of $\mathrm{P}_{\mathrm{a}} / \mathrm{P}_{\mathrm{n}}$. For the case where no radiation losse occurs, $\mathrm{P}_{\mathrm{a}} / \mathrm{P}_{\mathrm{n}}=1$, the temperature is high near the surface. As radiation loss increases the temperature at the surface drops producing an inverted temperature gradient.

The current depth is another important factor in the establishment of thermal gradients. For a given material this depends on the frequency of radiation and the part dimension. The dimensionless plot in figure 4 . shows the effect of varying the ratio $a / \delta$, on predicted thermal profiles. As the current depth increases relative to the radius of the part, large thermal gradients result. With the proper choice of frequency, and control of the radiative heat loss, thermal gradients can be established.

\section{EXPERIMENTAL}

A reactor consisting of a simple induction coil operated at $50 \mathrm{kHz}$ is illustrated in figure 5. Samples were heated without insulation to temperatures ranging from 1100 to $1400^{\circ} \mathrm{C}$. The preforms used were $3 \mathrm{D}$ carbon fiber (30 volume percent fiber, obtained from Hitco). These were cut into cylinders approximately 1 inch in diameter by 3 inches in length. The matrix was deposited by pyrolysis of methane at pressures ranging from 100 to 300 torr, with a flow rate of $200 \mathrm{sccm}$. Temperature gradients were monitored with thermocouples inserted in the preform at various radial positions.

\section{RESULTS}

For the process conditions of $1330^{\circ} \mathrm{C}, 100$ torr and $200 \mathrm{sccm}$ of methane the evolution of the temperature gradient from the centerline to the surface was monitored. 
Figure 6 shows this variation with time. The initial increase in $\Delta \mathrm{T}$ is thought to be caused by preferential deposition on the interior of the preform resulting in stronger coupling of the electromagnetic radiation to the center of the preform. The process is initially self propagating and the total absorbed power required continually decreases. Eventually as deposition near the exterior occurs the temperature gradient decreases. Materials have been processed to densities in the range of $1.7 \mathrm{~g} / \mathrm{cc}$ in as little as 30 hours. The matrix shows strong $\mathrm{sp}^{2}$ character as indicated by the raman spectra (figure 7 ), and $\mathrm{X}$-ray diffraction results.

Experiments were undertaken to evaluate the previously described model for the prediction of temperature gradients. A preform was infiltrated at $1100^{\circ} \mathrm{C}, 300$ torr and 200 sccm of methane. Temperatures were monitored at three positions; the center of the preform, approximately halfway from the center to edge, and near the edge. The total power into the part was $6 \mathrm{~kW}$. Values for the parameters used in the model are listed in table I.

\section{Table I. Model Parameters}

\begin{tabular}{|c|c|c|c|c|c|c|}
\hline $\begin{array}{c}\mathbf{f} \\
(\mathbf{k H z})\end{array}$ & $\begin{array}{c}\mathbf{P}_{\mathbf{n}} \\
\left(\mathbf{w} / \mathrm{cm}^{2}\right)\end{array}$ & $\begin{array}{c}\mathbf{P}_{\mathbf{a}} \\
\left(\mathbf{w} / \mathrm{cm}^{2}\right)\end{array}$ & $\begin{array}{c}\sigma \\
(\Omega \mathrm{m})^{-1}\end{array}$ & $\begin{array}{c}\delta \\
(\mathrm{cm})\end{array}$ & $\begin{array}{c}\mathbf{k} \\
\left(\mathbf{w} / \mathbf{m}^{2} \mathbf{o}\right)\end{array}$ & $\mathbf{a} / \delta$ \\
\hline \hline 50 & 7.75 & 26 & 25000 & 1.42 & 10 & 1 \\
\hline
\end{tabular}

The total emissive power was estimated according to: $\mathbf{E}=\varepsilon \sigma_{b} \mathbf{T}^{4}$. A reasonable

value of the emmisivity $\varepsilon$, for a rough porous carbon surface is 0.9 . One difficulty in the calculation is determining the correct radiating surface area. The effective radiating surface area for a carbon preform will be higher than the geometric area. A good estimate of the effect would require an adequate description of the fiber bundle and fiber bundle arrangement. Within such a model, view factors for individual fibers in the bundle, and individual bundles in the preform would need to be calculated. However, a simple model ignoring these details appears to give a reasonable result. Figure 8 describes the approximate arrangement of fibers within a bundle and the arrangement of bundles within the preform. The cylindrical shape of the fiber within the bundle leads to an increase in surface area by a factor of $\pi / 2$. Similarly, the effective surface area of the preform due to the cylindrical shape of the bundle is increased by a factor of $\pi / 2$. The effective surface area of the preform due to both these effects is increased by a total factor of $(\pi / 2)^{2}$, over the geometric surface area. Using this value, and the total power into the part, the corresponding absorbed and net power used in the calculation are obtained. The thermal conductivity was taken as effectively the same as that reported for an epoxy/graphite fiber composite adjusted for a 30 volume percent fiber loading (4). The results of the measurements along with the predicted initial gradients calculated from equation 3 are plotted in figure 9. Good agreement between the model predictions and the experimental data were obtained. Convective heat transfer coefficients were estimated and found to be negligible. 
Ultimately one would like to scale the process for large dimension parts. To maintain similar temperature gradients a lower frequency will be required. The results of the above experiment allow us to estimate the gradients for larger parts at different frequencies. Calculations for $10 \mathrm{kHz}$ frequency on a $10 \mathrm{~cm}$. diameter cylinder are shown in figure 10 . The predicted temperature gradients are similar to those calculated and measured for the 1 inch diameter part at $50 \mathrm{kHz}$.

\section{DISCUSSION}

The approach reduces processing times significantly. For example, typical carbon/carbon processing can run several months. Consequently, it is necessary to process hundreds of parts at time to reduce costs. Manufacturers are often left with many parts in inventory waiting for a customer. Furthermore, the large scale batch processes are not advantageous to maintaining quality. Variations from batch to batch and within batches can lead to low yields and reduced reliability. With short processing times the production rates of the batch process can be maintained while processing fewer parts. The ability to produce smaller quantities of parts reduces the costs incurred in maintaining large inventories. This allows manufacturers to take smaller orders and deliver in a reasonable time, or economically manufacture custom parts. Finally, improved quality and yield with the small batch process will be possible. For carbon/carbon materials, RF frequencies are required to heat the part effectively. This type of technology is commonly used in industrial heating. In most large scale processes, like the fabrication of carbon/carbon composites, RF induction heating is used to heat a susceptor which than radiates to the part. Using much of the same processing equipment the part can be heated directly to produce inverted gradients.

\section{CONCLUSIONS}

We have demonstrated a thermal gradient process for the rapid densification of carbon/carbon composites. High density material can be procduced in a as little as 30 hours. Initial temperature gradients have been predicted using a simple model and good agreement with experimental measurements was observed. The model can be used to estimate process conditions for large dimension parts.

\section{REFERENCES}

1. Besmann, T.M., Sheldon, B.W., Lowden, R.A., and Stinton, D.P., Science 253, 1104 (1991).

2. Devlin, D.J., Currier, R.P., Barbero, R.S., Espinoza, B.F., Cera. Eng. Sci. Proc. 14, 7-8 (1993).

3. A.C. Lind, L.N. Medgyesi-Mitschang, J.E Kurz, H.F. McKinney, and F.C. Wear, Mat. Res. Soc. Symp. Proc. Vol. 189, 1991.

4. Baker, R.M., Trans. AIEE 77, 106, (1958).

5. Engineered Materials HandBook, Vol 1, p414, 1988 


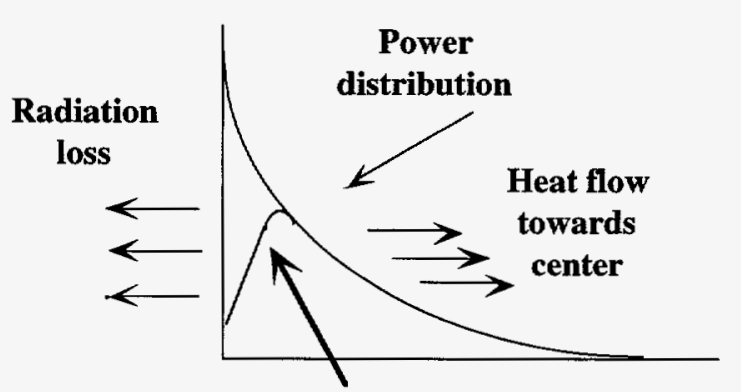

Temperature Distribution

Figure 1. The effect of volumetric heating on the temperature distribution.

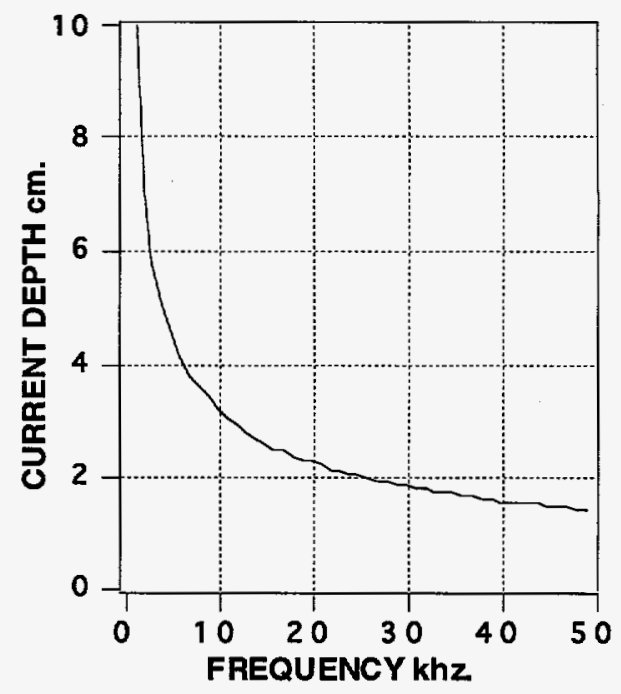

Figure 2. Variation of current depth

with frequency for carbon fiber preform.

Figure 4. The effect of varying the relative
current depth on the temperatue distribution.

Figure 4. The effect of varying the relative
current depth on the temperatue distribution.

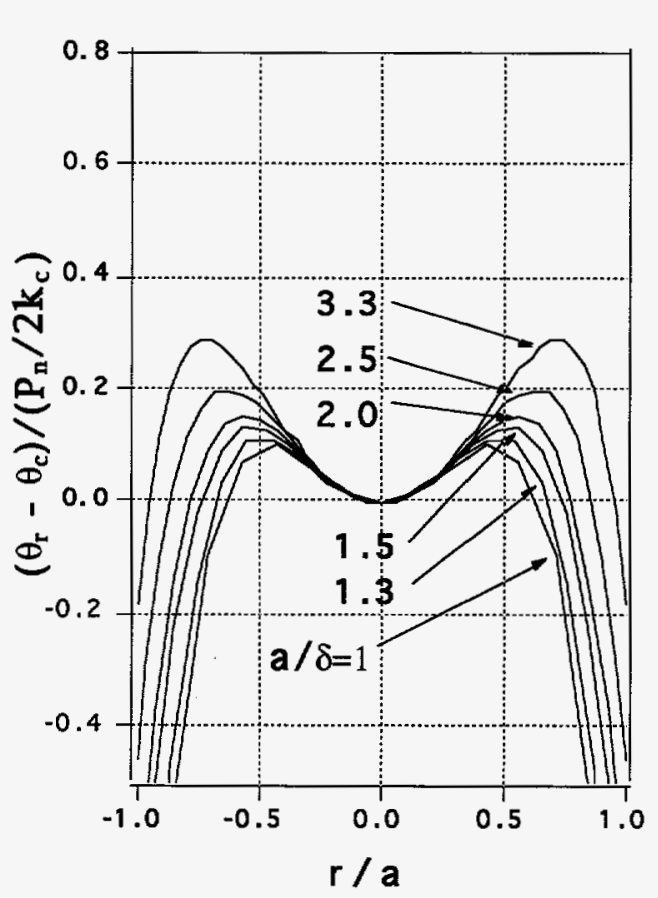

Figure 3. The effect of radiation loss on the temperature distribution.

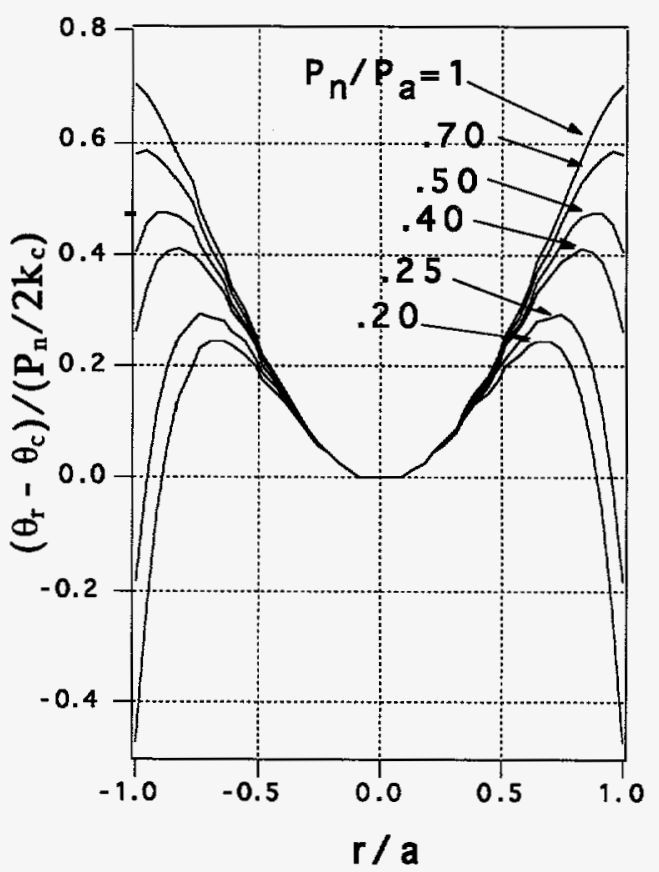


3D Carbon

fiber preform

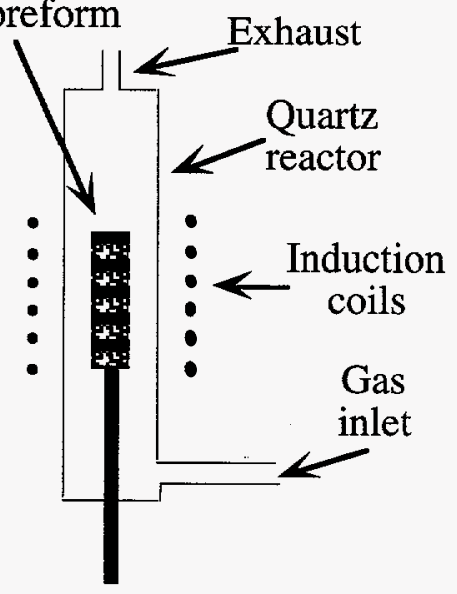

Figure 5. Schematic of the carbon/carbon composite reactor.

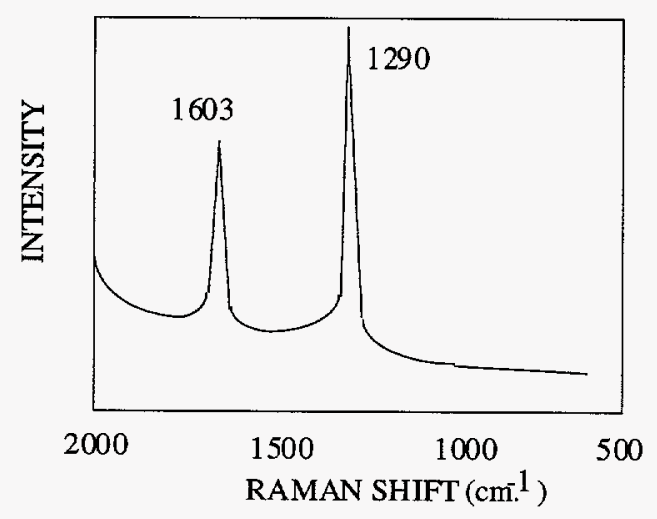

Figure 7. Raman spectra of matrix material produced by the inverted gradient process.

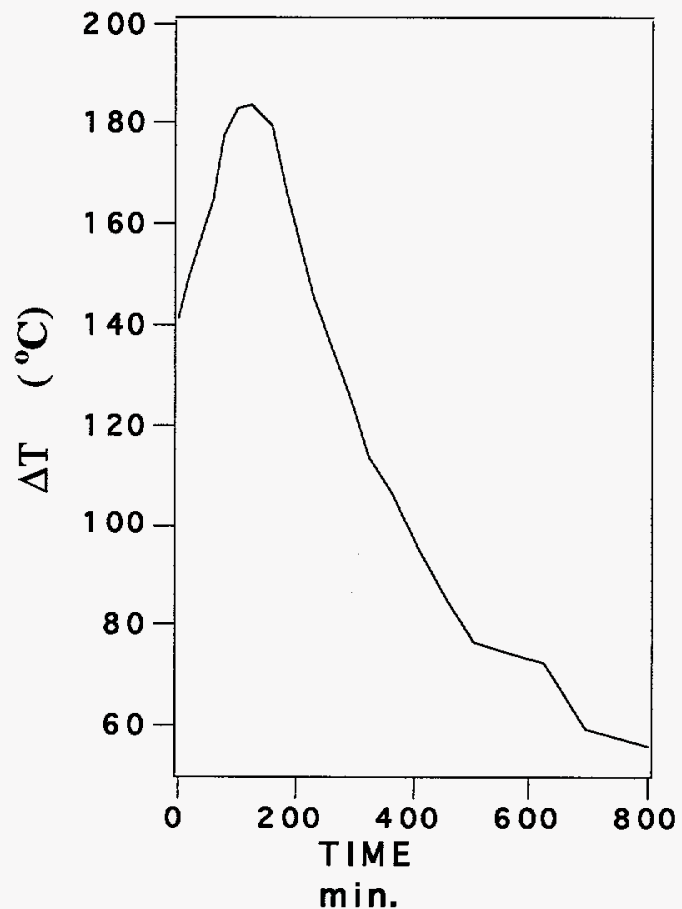

Figure 6. The variation in the temperature gradient as infiltration proceeds. 


\section{a

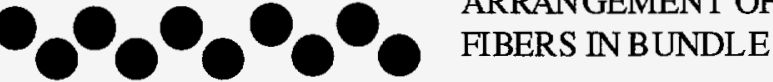 \\ ur人iun \\ EFFECTIVE SURFACE \\ AREA OF BUNDLE}

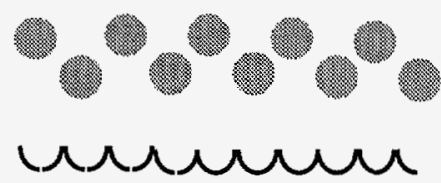

ARRANGEMENT OF

BUNDLES IN PREFORM

EFFECTIVE SURFACE

AREA OF PREFORM

TOTAL SURFACE AREA INCREASED BY A FACTOR OF $(\pi / 2)^{2}$ OVER THE GEOMETRIC SURFACE AREA

Figure 8. Approximate increase in surface area over geometric surface area of a carbon preform.

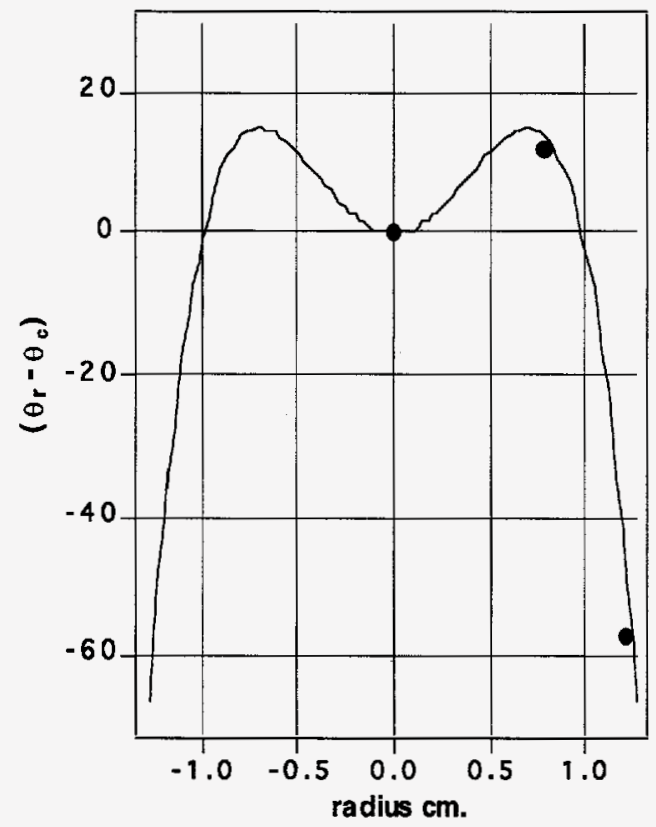

Figure 9. Comparison of experimentally measured temperaturegradient to model calculations for a 3-D carbon preform

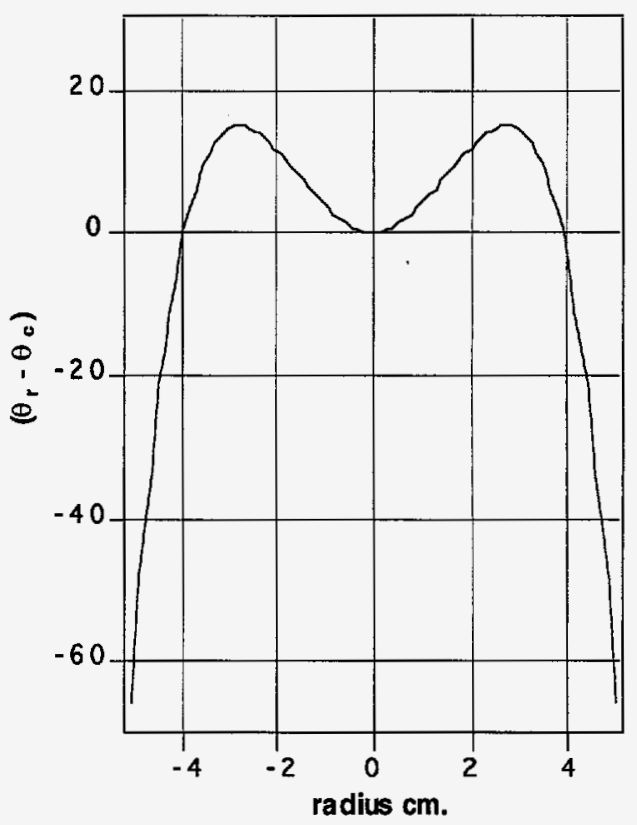

Figure 10. Predicted temperature gradientsfor a $10 \mathrm{~cm}$. diameter carbor preform processed at $10 \mathrm{kHz}$. 